Check for updates

Cite this: RSC Adv., 2018, 8, 21012

\title{
Structural and adsorption characteristics of potassium carbonate activated biochar
}

\begin{abstract}
Ling Zhu, (D) a Nan Zhao, ${ }^{\text {ab }}$ Lihong Tong ${ }^{a}$ and Yizhong Lv*a
Potassium carbonate activated biochar $\left(450^{\circ} \mathrm{C}, 600^{\circ} \mathrm{C}\right.$ and $\left.750{ }^{\circ} \mathrm{C}\right)$ and nonactivated biochar $\left(600^{\circ} \mathrm{C}\right)$ were prepared by using corn stalk as the raw material. These biochar samples were labeled as $\mathrm{KBC} 450$, $\mathrm{KBC} 600, \mathrm{KBC} 750$ and $\mathrm{BC} 600$. The physical and chemical properties of the biochar were strongly influenced by the activation of potassium carbonate. After activation with potassium carbonate, the aromatic, hydrophobic and non-polar properties of the biochar were enhanced to form an aromatized non-polar surface, and the aromatic properties were enhanced with the increase of the pyrolysis temperature. The outside surface of the activated biochar was similar to that of porous sponge with a mesoporous-microporous composite structure inside. The specific surface area of KBC600 was 5 times that of $\mathrm{BC} 600$, and $\mathrm{KBC750}$ had a maximum surface area of $815 \mathrm{~m}^{2} \mathrm{~g}^{-1}$. Batch adsorption experiments showed that the adsorption capacity of KBC for naphthalene increased with the increase of pyrolysis temperature. The adsorption capacity of the biochar for naphthalene showed a significant positive correlation with $\mathrm{O} / \mathrm{C}$ and $(\mathrm{O}+\mathrm{N}) / \mathrm{C}$. KBC750 with the strongest surface hydrophobicity and the largest specific surface area had the largest adsorption capacity of $130.7 \mathrm{mg} \mathrm{g}^{-1}$. Physical adsorption and $\pi-\pi$ EDA were the main adsorption mechanisms.
\end{abstract}

Received 18th April 2018
Accepted 1st June 2018

DOI: $10.1039 / \mathrm{c} 8 \mathrm{ra} 03335 \mathrm{~h}$

rsc.li/rsc-advances

Due to the improvement of pore structure and surface

\section{Introduction}

The use of effective and low-cost recyclable materials to control pollution is an environmentally sustainable development method. Biochar is a carbonaceous material formed by pyrolysis of biomass (such as straw, poplar leaf, sawdust, etc.) under anoxic conditions. ${ }^{\mathbf{1 , 2}}$ Biochar has been widely used in water and soil remediation as an environmentally friendly material, ${ }^{3}$ due to its excellent surface and strong adsorption properties. The application of biochar in pollution control depends on its surface characteristics. The activation of biochar in the preparation process is the main pathway to improving its surface properties. Activated biochar has received increasing attention in recent years due to its well-developed porous structures, large surface area and wide spectrum of surface functional groups. Physical activation and chemical activation are two major ways to activate biochar. Chemical activation gets more attention, because it can combine carbonization and activation simultaneously, and the chemically activated biochar could develop better porous structures than that from physical activation. ${ }^{4} \mathrm{~A}$ great deal of chemicals can be used to activate biochar, such as $\mathrm{ZnCl}_{2}, \mathrm{KOH}, \mathrm{NaOH}, \mathrm{H}_{3} \mathrm{PO}_{4}$ and $\mathrm{NH}_{3} \cdot \mathrm{H}_{2} \mathrm{O}$, etc. ${ }^{5-9}$

${ }^{a}$ College of Resources and Environmental Sciences, China Agricultural University, Beijing 100193, China. E-mail: lyz@cau.edu.cn

${ }^{b}$ Guangdong Provincial Key Lab of Environmental Pollution Control and Remediation Technology, School of Environmental Science and Engineering, Sun Yat-sen University, Guangzhou 510275, China chemical property, activated biochar usually has better adsorption capacity. It is believed that the increase of micropores will increase the adsorption capacity of biochar. Microporosity of $\mathrm{H}_{2} \mathrm{SO}_{4}$ activated biochar derived by pork bones increased by $263 \%$, and the maximum adsorption capacity of methylene blue reached $61.3 \mathrm{mg} \mathrm{g}^{-1}$, which was nearly 3 times of that of unactivated biochar. ${ }^{10}$ It is noteworthy that many studies have shown that mesopores seem to be more suitable for adsorption of organic pollutants. In the study of the relationship between pore development and biochar adsorption properties, it was found that the adsorption capacity was mainly determined by biochar mesopores (1.7-50 nm) rather than its total area, and most micropores in biochar were not accessible to most nanoscale organic molecules. ${ }^{\mathbf{1 1}}$ Not all activators enhance the specific surface area of biochar. Some of these activators mainly change the surface chemical properties of biochar, such as surface functional group composition and surface aromaticity. Surface chemical property is also one of the important properties that determine the biochar adsorption capacity. Activators have a significant effect on the surface chemical property of biochar. After $\mathrm{HCl}$ and $\mathrm{HF}$ elution, the carbon content, hydrophobicity and the aromatic functional group content were increased, while the polarity aliphatic chain char and hydroxyl were decreased, and these changes improved the adsorption of 2,4-D on biochar. ${ }^{12}$ Compared with acidmodified BC, alkali treatment would result in a larger surface area with higher surface aromaticity ratio $(\mathrm{H} / \mathrm{C})$ and higher N/C 
ratio with lower $\mathrm{O} / \mathrm{C}$ values. ${ }^{13}$ Organic solvents also affect the surface properties of biochar. Since the changes of oxygencontaining functional group changed the interaction of $\pi-\pi$ electron-donor-acceptor between modified biochar and tetracycline, the methanol-modified biochar increased the adsorption capacity of tetracycline by $45.6 \%$ compared with the primary biochar. ${ }^{14,15}$

Many studies have been conducted on the use of $\mathrm{KOH}$ as activator to activate biochar. The activation of $\mathrm{KOH}$ is mainly reflected in the increase of the number of mesoporous and specific surface area. Compared with physical activation, chemical activation using $\mathrm{KOH}$ usually results in a larger specific surface area with pores concentrated in a smaller pore size range. The increase of specific surface area makes the biochar activated by KOH have larger adsorption capacity. After activation by $\mathrm{KOH}$, the mesoporous amount of potato straw biochar increased and the adsorption capacity of ciprofloxacin was enlarged..$^{16}$ After activated by $\mathrm{KOH}$, the specific surface area of municipal solid waste biochar increased by $64 \%$, and the removal rate of methylene blue reached $99 \% .{ }^{17}$ Actually, $\mathrm{K}_{2} \mathrm{CO}_{3}$ was formed in the activation process of $\mathrm{KOH}$. The hydrolysis of $\mathrm{K}_{2} \mathrm{CO}_{3}$ can also produce $\mathrm{KOH}$, and compared to $\mathrm{KOH}, \mathrm{K}_{2} \mathrm{CO}_{3}$ is less corrosive, safer to use and easier to store. $\mathrm{K}_{2} \mathrm{CO}_{3}$ is a potential activator, but the effects of $\mathrm{K}_{2} \mathrm{CO}_{3}$ on the surface properties and adsorption behaviors of biochar were rarely reported. Meanwhile, in previous studies, biochar was immersed in activator solution. There are few studies on the preparation of activated biochar by directly impregnating biomass with activator solution. Therefore, $\mathrm{K}_{2} \mathrm{CO}_{3}$ was selected as activator in this study, and the straw is immersed in $\mathrm{K}_{2} \mathrm{CO}_{3}$ solution directly. Scanning electron microscopy, specific surface area and pore size distribution, infrared spectra were used for determining the structural characteristics and functional groups of biochars. The purpose of the study was to investigate the changes of surface characteristics for biochar after being activated by $\mathrm{K}_{2} \mathrm{CO}_{3}$, and naphthalene was used as adsorbate to study the adsorption characteristics and mechanism of biochar on nonpolar pollutants.

\section{Materials and methods}

\subsection{Materials}

All chemicals used in the experiments at analytical purity were purchased from Sinopharm Group Chemical Reagent Co., Ltd. Corn straw collected from Shang Zhuang experimental station of China Agricultural University in Beijing, China, was dried in an oven at $80^{\circ} \mathrm{C}$ for $24 \mathrm{~h}$, and then crushed by pulverizer.

\subsection{Activated biochar preparation}

The corn straws were impregnated in potassium carbonate solution $\left(1 \mathrm{~g}\right.$ of straw mixed with $\left.3 \mathrm{~mL} 0.6 \mathrm{~mol} \mathrm{~L}^{-1} \mathrm{~K}_{2} \mathrm{CO}_{3}\right)$ for $24 \mathrm{~h}$. After that, the mixture was dried at $80^{\circ} \mathrm{C}$. Subsequently, the dried mixture was pyrolyzed in muffle furnace with a heating rate of $10{ }^{\circ} \mathrm{C} \mathrm{min}^{-1}$. The pyrolysis temperatures were set as $450{ }^{\circ} \mathrm{C}, 600{ }^{\circ} \mathrm{C}$ and $750{ }^{\circ} \mathrm{C}$, respectively, and the holding time was $2 \mathrm{~h}$. The obtained activated biochars were ground to pass
$0.25 \mathrm{~mm}$ sieve. The biochars were mixed with $1 \mathrm{~mol} \mathrm{~L}^{-1} \mathrm{HF}$ and $\mathrm{HCl}$ to remove the ash, and then washed with deionized water until the conductivity of the wash liquor was less than 10 $\mu \mathrm{S} \mathrm{cm}^{-1}$. At last, the biochars were dried at $105^{\circ} \mathrm{C}$. The control biochar was prepared directly from corn stalk at $600{ }^{\circ} \mathrm{C}$, without impregnation and addition of potassium carbonate. The biochars were labeled as KBC450, KBC600, KBC750, BC600 (K indicated the addition of potassium carbonate, $\mathrm{BC}$ indicated the biochar, and the number was the pyrolysis temperature). The samples were stored in airtight containers for further analysis. All reagents used were analytical grade.

\subsection{Biochars characterization}

The $\mathrm{pH}$ was measured at a ratio of biochar to solvent $1: 2.5$ $(m: v)$. The contents of $\mathrm{C}, \mathrm{H}$ and $\mathrm{N}$ in the biochars were analyzed by elemental analysis (Vario EL III®, Germany). The surface morphology of the biochars were characterized by SEM (S-4800, Hitachi®, Japan). The adsorption and desorption isotherms of the samples were measured by specific surface area and pore analyzer (ASAP2020®, the United States) at $77 \mathrm{~K}$. The total specific surface area and the average pore size were calculated by Brunauer-Emmett-Teller (BET) method. The total pore volume was obtained by converting the liquid nitrogen adsorption capacity at a relative pressure of 0.99 into volume. The microporous pore volume and specific surface area were calculated by $t$-plot method. The mesopore and macropore specific surface area were calculated by Barrett-Joyner-Halenda (BJH) method. Burning method was applied to determine the ash content of biochars, briefly, a small amount of biochar placed in the muffle furnace and burned at $750{ }^{\circ} \mathrm{C}$ for $4 \mathrm{~h} .{ }^{18,19}$ Infrared microspectroscopy was used to characterize the functional groups on the surface of biochars. The IR microspectra were recorded in the range of $4000-400 \mathrm{~cm}^{-1}$ with a resolution of $4 \mathrm{~cm}^{-1}$ using a Nicolet Nexus-470 FTIR spectrometer (Thermo Nicolet, San Diego, CA, USA).

\subsection{Adsorption experiments}

Naphthalene (purity $\geq 99 \%$ ) was obtained from J\&K Scientific Co., Ltd. Stock naphthalene solution $\left(1000 \mathrm{mg} \mathrm{L}^{-1}\right)$ was prepared by dissolving naphthalene in absolute ethanol and stored in a $4{ }^{\circ} \mathrm{C}$ refrigerator under darkness. For isotherm studies, $50 \mathrm{~mL}$ conical flask was filled with $30 \mathrm{~mL}$ naphthalene solution of different concentrations at $30{ }^{\circ} \mathrm{C}$. For KBC450, KBC600 and BC600, the concentration gradient is 16$30 \mathrm{mg} \mathrm{L}^{-1}$, while the concentration gradient is $32-48 \mathrm{mg} \mathrm{L}^{-1}$ for KBC750. $10 \mathrm{mg}$ of biochar were added to each bottle and agitated at $150 \mathrm{rpm}$ for $24 \mathrm{~h}$. After that, the mixture was filtered through a $0.22 \mu \mathrm{m}$ filter. The residual naphthalene in the filtrate was measured at $219 \mathrm{~nm}$ by UV spectrophotometry (UV-1800PC, Shanghai Jinghua). Each adsorption experiment was determined in triplicate, and control was set.

The data obtained by the isothermal adsorption experiment were fitted with the Langmuir model (eqn (1)) and the Freundlich model (eqn (2)), respectively. 


$$
\begin{aligned}
& \text { Langmuir : } q_{\mathrm{e}}=\frac{q_{\mathrm{m}} C_{\mathrm{e}}}{1 / b+C_{\mathrm{e}}} \\
& \text { Freundlich: } q_{\mathrm{e}}=k_{\mathrm{f}} C_{\mathrm{e}}^{1 / n}
\end{aligned}
$$

$q_{\mathrm{m}}\left(\mathrm{mg} \mathrm{g}^{-1}\right)$ represents the maximum adsorption capacity, $C_{\mathrm{e}}$ $\left(\mathrm{mg} \mathrm{L}^{-1}\right)$ is the adsorbent concentration at equilibrium, $b\left(\mathrm{~L} \mathrm{mg}^{-1}\right)$ is the adsorption equilibrium constant, $k_{\mathrm{f}}\left(\mathrm{mg}^{1-1 / n} \cdot \mathrm{L}^{1 / n} \cdot \mathrm{g}^{-1}\right)$ is the affinity coefficient, $n$ is the Freundlich constant.

\section{Results and discussion}

\subsection{Basic properties of biochar activated by potassium carbonate}

The basic physical and chemical properties of KBC and BC600 are shown in Table 1 . The yield of biochar decreased with the increase of pyrolysis temperature. In the acidic condition, some of the original metal ions and silicon ions combining with the oxygen-containing functional groups may be replaced by $\mathrm{H}^{+}$, so acid-treated biochar surface appears acidic.

The carbon and hydrogen content of KBC increased with the temperature rising. At $600{ }^{\circ} \mathrm{C}$, the carbon content of BC600 was lower than KBC600 and exhibited a higher hydrogen content, which indicated that potassium carbonate could promote the carbonation reaction and accelerate the dehydrogenation. With increasing temperature, the oxygen and nitrogen contents of KBC showed no regular changes but all lower than BC600, indicating that the addition of potassium carbonate made nitrogen and oxygen more easily lost. The atomic ratio could be used to characterize the aromaticity, hydrophobicity, and polarity of biochar. With the increase of $\mathrm{O} / \mathrm{C},(\mathrm{O}+\mathrm{N}) / \mathrm{C}$ and $\mathrm{H} / \mathrm{C}$, the hydrophilicity and polarity increased while aromaticity decreased. ${ }^{20}$ The hydrophobicity and nonpolarity of BC600 were less than KBC, and the aromaticity was less than KBC600 and KBC750. The aromaticity of KBC450 was smaller than that of BC600, which might be caused by the lower pyrolysis temperature. The difference between BC600 and KBC showed that the addition of potassium carbonate during the preparation could change the pyrolysis process of biomass. $\mathrm{H} / \mathrm{C}$ of $\mathrm{KBC}$ decreased with the increasing pyrolysis temperature. $\mathrm{O} / \mathrm{C},(\mathrm{O}+\mathrm{N}) / \mathrm{C}$ of KBC450 and KBC600 did not change with the temperature increasing, while KBC750 was decreased. Therefore, the hydrophobicity and nonpolarity of KBC450 and KBC600 did not change significantly with the increase of temperature, and the hydrophobicity and nonpolarity of KBC750 were enhanced. Zhang et al. (2016) have shown that the addition of potassium carbonate and the formation of potassium hydroxide during the impregnation process would destroy the cellulose structure, weaken the hydrogen bonds between the cellulose molecules, and reduce the activation energy of the reaction, so that the pyrolysis of high polymer molecules in a high temperature conditions were more thorough. ${ }^{21}$ Nishimura et al. (2009) showed that $\mathrm{K}^{+}$reacted with the glycosidic linkages of the cellulose polysaccharide units under high temperature conditions and changed the cellulose structure under the combined action of carbon dioxide. Compared with the classical levoglucosan structure, ${ }^{22}$ the final structure was a ring-opening polyhydroxy structure and forms $\mathrm{O}^{-} \mathrm{K}^{+}$structure. ${ }^{23}$ Under these structural conditions, the addition and polycondensation reaction would be easier, and the polarity and hydrophilicity would be decreased. Under acid conditions, $\mathrm{K}^{+}$will be replaced by $\mathrm{H}^{+}$, which was one of the reasons why the acidity of KBC was stronger than BC600.

\subsection{Surface micro-morphology characteristics of KBC surface}

The SEM images of KBC and BC600 are shown in Fig. 1. KBC450 and KBC600 was granular and had a smooth surface with uniform pore distribution. The surface of KBC750 was rough and the pore distribution was high. BC600 was fragmented, and most of its pores were the original xylem or vascular pores of straw, and the new pores were rare. Although there were many pores in KBC750, the fragmentation of pore wall may had a negative effect on the adsorption capacity.

It could be speculated that potassium carbonate was dispersed on the surface of the straw or into the cellulosic internal structure after immersion. It was reported that around $700{ }^{\circ} \mathrm{C}$, the reaction (3) would occur. ${ }^{24}$ The metallic $\mathrm{K}$ could further develop porosity by intercalation through carbon sheets to enlarge the pores. Due to the removal of tarry material within the pores, microporous and mesoporous could also be developed at the temperature blow $600{ }^{\circ} \mathrm{C}$. $^{23}$

$$
\mathrm{K}_{2} \mathrm{CO}_{3}+2 \mathrm{C} \rightarrow 2 \mathrm{~K}+3 \mathrm{CO}
$$

Under high temperature conditions, potassium carbonate catalyzed the gasification of cellulose, ${ }^{23}$ and the small amount of potassium carbonate that attached to the biomass surface

Table 1 Elemental composition, $\mathrm{pH}$ and ash content of potassium carbonate activated maize straw biochar $^{a}$

Element content $\%$

Sample

KBC450

KBC600

KBC750

BC600

C

$\mathrm{C}$

79.88

80.79

88.90

73.83

${ }^{a} \mathrm{O} \%=100 \%-\mathrm{C} \%-\mathrm{H} \%-\mathrm{N} \%-a s h \%$, the ash contains a small amount of $\mathrm{P}, \mathrm{S}$.

\begin{tabular}{|c|c|c|c|c|c|c|c|c|}
\hline $\mathrm{H}$ & $\mathrm{N}$ & $\mathrm{O}$ & $\mathrm{H} / \mathrm{C}$ & $\mathrm{O} / \mathrm{C}$ & $\mathrm{N}) / \mathrm{C}$ & Yield\% & Ash\% & $\mathrm{pH}$ \\
\hline 3.42 & 1.07 & 13.53 & 0.51 & 0.13 & 0.14 & 35.0 & 2.10 & 3.37 \\
\hline 2.42 & 0.89 & 13.79 & 0.36 & 0.13 & 0.14 & 31.8 & 2.11 & 3.53 \\
\hline 1.39 & 1.19 & 7.09 & 0.18 & 0.06 & 0.07 & 30.2 & 1.43 & 3.88 \\
\hline 2.77 & 2.55 & 16.76 & 0.45 & 0.17 & 0.20 & 45.8 & 4.10 & 4.33 \\
\hline
\end{tabular}

Atomic ratio

$(\mathrm{O}+$ 

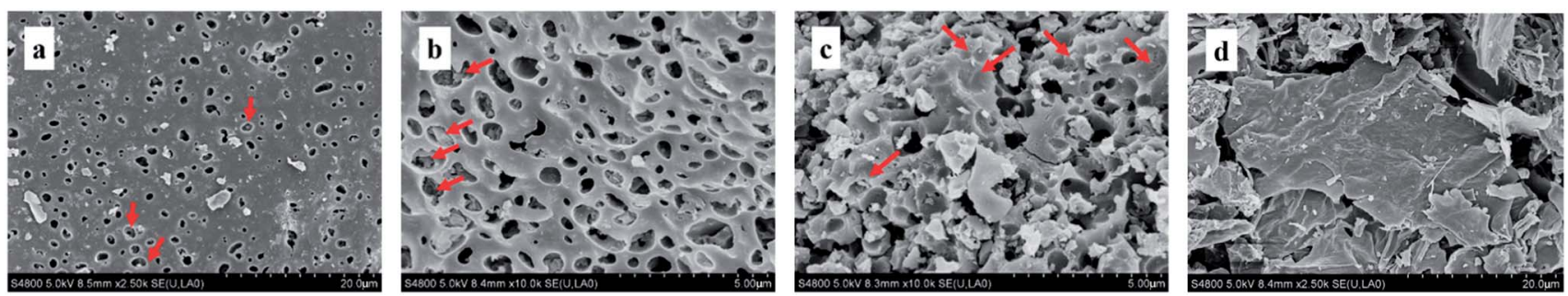

Fig. 1 SEM images of KBC/BC600 ( $a, b, c$, d expressed KBC450, KBC600, KBC750, BC600 respectively. Red arrows indicate non-penetrating pits).

reacted with the surrounding cellulose molecules, leaving the non-penetrating pits. This structure was clearly observed in the electron microscopy of KBC450, KBC600 and KBC750, but not on the surface of BC600. If the amount of potassium carbonate that attached to the surface was sufficient, potassium carbonate would react with cellulose continuously and form penetrating pores. The potassium carbonate inside the cellulose would leave pores in the interior and cross link with each other. The higher the temperature, the more complete the gasification reaction, the higher the pores density. The porous property of KBC was more favorable to the diffusion of pollutants into the interior, which has positive significance to improve the adsorption characteristics.

\subsection{Analysis of pore structure characteristics of KBC}

Adsorption and desorption curve of $\mathrm{N}_{2}$ are shown in Fig. 2 . When the relative pressure was less than 0.3 , the adsorption capacity increases rapidly. According to the Kelvin formula, when the relative pressure is 0.3 , the corresponding pore radius was less than $1.5 \mathrm{~nm}$. At this stage, monomolecular adsorption occurred and no capillary condensation happened. When the relative pressure was $0.3-0.7$, the slope was so small and became almost a platform. It indicated that multilayer adsorption occurred at this stage. When the relative pressure was greater than 0.8 , the adsorption/desorption curves appeared tailing, showing a large increase in adsorption capacity, which was mainly caused by the capillary condensation of mesopores and macropores. The hysteresis loops of $\mathrm{KBC}$ were Type $\mathrm{H} 4$,

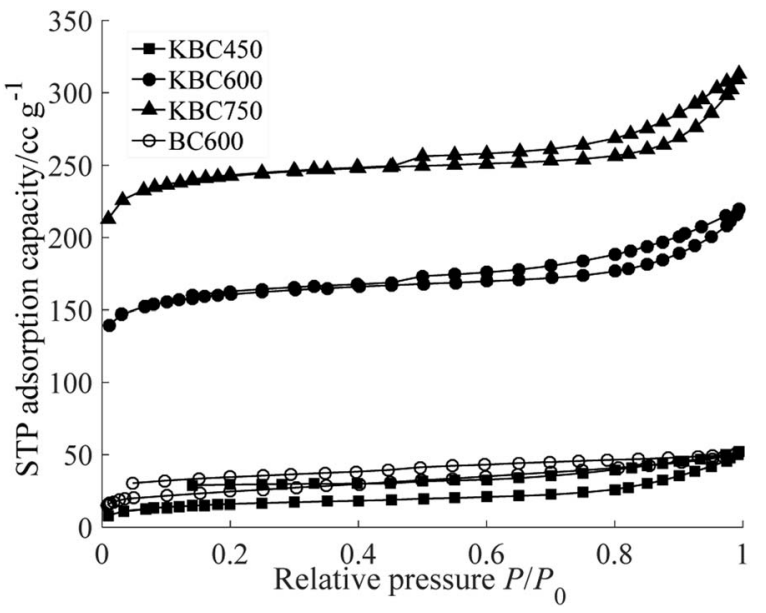

Fig. $2 \mathrm{~N}_{2}$ adsorption-desorption curve of biochar. which showed the existence of micro-mesoporous composite structure, ${ }^{25}$ and it would be conducive to the adsorption. The hysteresis loops of KBC450 and BC600 were not closed, which may be caused by the less content of mesoporous. The hysteresis loops of the KBC600 and KBC750 were closed at relative pressure of about 0.4 , indicating an increased proportion of mesopores volume. ${ }^{26}$

The specific surface area and pore size parameters of KBC and BC600 are shown in Table 2. The activation effect of potassium carbonate was affected by the pyrolysis temperature. With the increasing pyrolysis temperature, the specific surface area and total pore volume of KBC were increased. The BET surface area of KBC750 was the highest, reached $814.89 \mathrm{~m}^{2} \mathrm{~g}^{-1}$. When the pyrolysis temperature was $450^{\circ} \mathrm{C}$, the specific surface area and pore volume of micropores were smaller than mesoporous and macropore. When the pyrolysis temperature was rising to $600{ }^{\circ} \mathrm{C}$ and $750{ }^{\circ} \mathrm{C}$, the specific surface area and pore volume of micropores were larger than mesoporous and macropore. It showed that potassium carbonate mainly increased the mesoporous and macroporous at low pyrolysis temperature, and the micropores would increase when the activation temperature was high. The average pore size decreased with the increase of activation temperature, which indicated that the possibility of micropores increased with the rising activation temperature.

Potassium carbonate had a significant effect on the specific surface area and pore structure. Compared with the unactivated biochar, the specific surface area of KBC600 was 5 times that of

Table 2 Surface area and aperture parameter of KBC samples ${ }^{a}$

\begin{tabular}{lcccc}
\hline Sample & KBC450 & KBC600 & KBC750 & BC600 \\
\hline$S_{\text {BET }}\left(\mathrm{m}^{2} \mathrm{~g}^{-1}\right)$ & 57.80 & 541.91 & 814.89 & 86.75 \\
$V_{\mathrm{T}}\left(\mathrm{mL} \mathrm{g}^{-1}\right)$ & 0.081 & 0.339 & 0.478 & 0.079 \\
$S_{\text {ex }}\left(\mathrm{m}^{2} \mathrm{~g}^{-1}\right)$ & 46.57 & 114.77 & 125.85 & 60.38 \\
$S_{\text {mic }}\left(\mathrm{m}^{2} \mathrm{~g}^{-1}\right)$ & 11.23 & 427.14 & 689.04 & 26.37 \\
$S_{\mathrm{m}}\left(\mathrm{m}^{2} \mathrm{~g}^{-1}\right)$ & 33.69 & 71.46 & 72.61 & 19.99 \\
$V_{\text {mic }}\left(\mathrm{mL} \mathrm{g}^{-1}\right)$ & 0.004 & 0.198 & 0.32 & 0.012 \\
$V_{\mathrm{m}}\left(\mathrm{mL} \mathrm{g}^{-1}\right)$ & 0.072 & 0.124 & 0.143 & 0.03 \\
BET average & 4.91 & 2.38 & 2.27 & 3.79
\end{tabular}

pore width $(\mathrm{nm})$

${ }^{a} S_{\mathrm{BET}}$ stands for BET specific surface area; $V_{\mathrm{T}}$ for total pore volume; $S_{\mathrm{ex}}$ for $t$-plot external specific surface area; $S_{\text {mic }}$ for $t$-plot micropore specific surface area; $S_{\mathrm{m}}$ for mesoporous and macroporous surface area; $V_{\mathrm{mic}}$ for $t$-plot micropore volume; $V_{\mathrm{m}}$ for mesoporous and macroporous pore volume. 
BC600, and the total pore volume, micropores area and outward surface area of KBC600 were significantly larger than BC600. The BET average pore size of BC600 was greater than that of KBC600 and KBC750, indicating that the addition of potassium carbonate may increase the distribution of micropores. Compared with other activators, biochar was significantly activated by potassium carbonate. The specific surface area of biochar that activated by $\mathrm{KOH}$ at $500{ }^{\circ} \mathrm{C}$ was only $59 \mathrm{~m}^{2} \mathrm{~g}^{-1,27}$ meanwhile $\mathrm{HCl}$ activated kenaf fibre char was $346.5 \mathrm{~m}^{2} \mathrm{~g}^{-1},,^{28}$ and $\mathrm{H}_{3} \mathrm{PO}_{4}$ activated biochar derived by corn stalk under $550{ }^{\circ} \mathrm{C}$ had mesoporous structure with $S_{\mathrm{BET}}$ of $600 \mathrm{~m}^{2} \mathrm{~g}^{-1} \cdot{ }^{29}$ The specific surface area of KBC600 and KBC750 prepared by this method was significantly larger. Over all, using potassium carbonate as the activator has a significant effect on increasing the pore complexity of biochar, forming and optimizing the composite pore structure. This effect was more prominent at high temperature.

Fig. 3 shows the mesoporous pore size distribution of $\mathrm{KBC}$ and $\mathrm{BC} 600$. The result suggested that the pores of $\mathrm{KBC}$ were distributed centrally over 2-4 $\mathrm{nm}$ and 6-125 $\mathrm{nm}$. Compared with $\mathrm{KBC}$, the mesoporous distribution of $\mathrm{BC}$ in the range of $3-$ $9 \mathrm{~nm}$ was more than that of $\mathrm{KBC}$, but the mesoporous distribution with larger pore size $(8-50 \mathrm{~nm})$ wasn't dominant. With the increase of pyrolysis temperature, the number of microporous, pore density and specific surface area were increased, which showed that potassium carbonate played a role in increasing both the internal micropores and mesopores distribution. The macroporous spread on the exterior densely, and the micro-mesopore composite structure distributed on the inner surface would facilitate the diffusion of contaminant molecules into the biochar.

\subsection{Adsorption mechanism of naphthalene on KBC}

The results of KBC and BC600 adsorption isotherms of naphthalene are shown in Fig. 4. Adsorption isotherms are L-type. The fitting parameters of each model are shown in Table 3. According to the determination coefficient, Langmuir and Freundlich model were well fitted to KBC450, KBC600 and BC600, and the Freundlich model was well fitted to KBC750.
The Freundlich model is suitable for multi-layer adsorption of non-uniform surface, which was consistent with the surface morphology and the specific surface area of KBC750. According to Langmuir model, the maximum adsorption capacities of BC600, KBC450 and KBC600 to naphthalene were $43.06 \mathrm{mg} \mathrm{g}^{-1}$, $63.25 \mathrm{mg} \mathrm{g}^{-1}$ and $70.05 \mathrm{mg} \mathrm{g}^{-1}$, respectively. The Freundlich constant of isothermal curve was $1 / n<1$, indicating that the adsorption isotherm belongs to $L$ type, and the value is between 0.1 and 0.5 , indicating that the adsorption of naphthalene on the surface of KBC was easy. The structure of KBC had an important effect on the adsorption capacity. The structural changes were closely related to the activation of potassium carbonate at different pyrolysis temperatures. The higher the pyrolysis temperature was, the more intense the gasification reacted inside and outside of the biomass, and the more developed the porosity was. ${ }^{30}$

The correlation analysis was used to analyze the influence of the chemical and structural properties of the biochar on the adsorption performance. The results are shown in Table $4 . k_{\mathrm{f}}$ is the adsorption constant of Freundlich model, and its value is related to the adsorption capacity and adsorption strength. $n$ could characterize the interaction strength between adsorbate and adsorbent surface, and the larger the value of $n$, the stronger the interaction. ${ }^{31}$ There was a negative correlation between $\mathrm{H} / \mathrm{C}$ and $q_{\mathrm{m}}$, and the negative correlation between $\mathrm{H} / \mathrm{C}$ and $n, k_{\mathrm{f}}$ reached a significant level, indicating that the increase of aromaticity would enhance the affinity of naphthalene with biochars surface and promote the adsorption of naphthalene to form larger adsorption capacity. There was also a similar relationship between $\mathrm{O} / \mathrm{C},(\mathrm{O}+\mathrm{N}) / \mathrm{C}$ and $q_{\mathrm{m}}, n, k_{\mathrm{f}}$, which mean that the adsorption of naphthalene by $\mathrm{KBC}$ was significantly related to the hydrophilicity and polarity of biochar, and the non-polar hydrophobic surface was more conducive to the adsorption of naphthalene. The polarity and hydrophilicity of biochar occupy the dominant position in the adsorption of naphthalene, and the increase in oxygen-containing functional groups, such as carbonyl, carboxyl, and ether groups, reduces the sites available for naphthalene adsorption on the surface. ${ }^{32}$

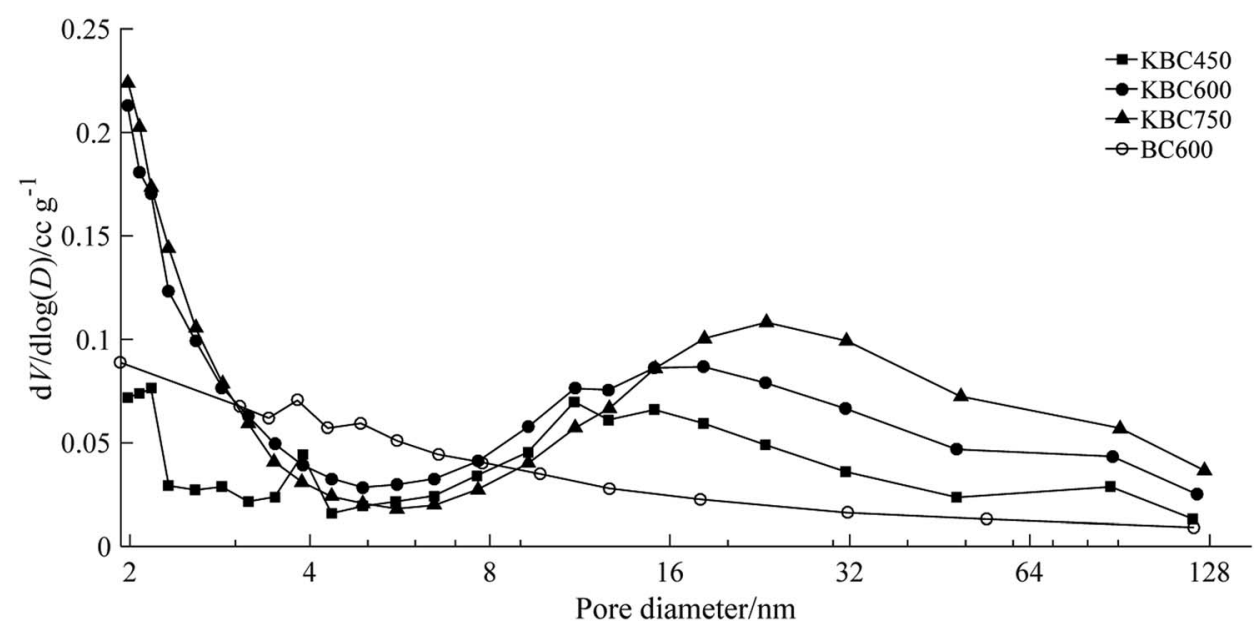

Fig. 3 Mesopore distribution calculated by BJH model. 

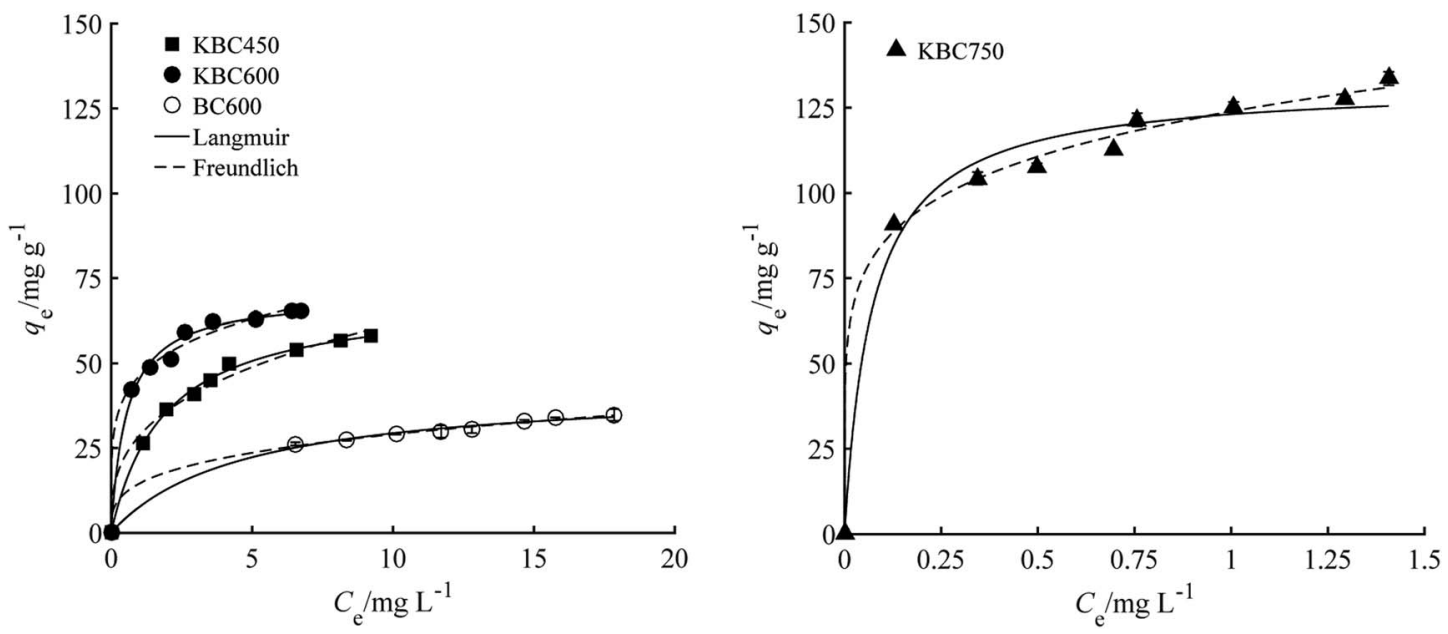

Fig. 4 The adsorption isotherms fitting of biochar.

Table 3 Parameters of Langmuir and Freundlich model of adsorption isotherms of naphthalene on biochars

\begin{tabular}{|c|c|c|c|c|c|c|}
\hline \multirow[b]{2}{*}{ Sample } & \multicolumn{3}{|l|}{ Langmuir } & \multicolumn{3}{|c|}{ Freundlich } \\
\hline & $b / \mathrm{L} \mathrm{mg}^{-1}$ & $q_{\mathrm{m}} / \mathrm{mg} \mathrm{g}^{-1}$ & $R^{2}$ & $k_{\mathrm{f}}$ & $1 / n$ & $R^{2}$ \\
\hline KBC450 & 0.370 & 63.25 & 0.9922 & 22.23 & 0.372 & 0.9898 \\
\hline КBC600 & 1.92 & 70.05 & 0.9962 & 47.10 & 0.184 & 0.9909 \\
\hline KBC750 & 15.56 & 130.70 & 0.9761 & 123.79 & 0.153 & 0.9945 \\
\hline BC600 & 0.214 & 43.06 & 0.9943 & 14.49 & 0.302 & 0.9973 \\
\hline
\end{tabular}

$S_{\mathrm{BET}}, V_{\mathrm{T}}, V_{\mathrm{mes}}, V_{\text {mic }}$ and $q_{\mathrm{m}}, n, k_{\mathrm{f}}$ showed a positive correlation. It was noteworthy that the specific surface area of KBC600 was 9.38 times that of $\mathrm{KBC} 450$, but the saturation adsorption capacity fitted by Langmuir equation was similar. Similarly, the specific surface area of BC600 was 1.5 times that of KBC450, but the maximum adsorption capacity was lower than that of $\mathrm{KBC} 450$. When the pyrolysis temperature was raised to $750{ }^{\circ} \mathrm{C}$, the specific surface area of KBC750 increased by 1.5 times compared with that of KBC600, but the adsorption capacity increased nearly twice. The above observations showed that the specific surface area was not the only determinant of naphthalene adsorption by KBC, surface chemical properties also play an important role. The improvement of pore structure, such as the increase of mesopores and micropores, would promote the diffusion of naphthalene and its interaction with the surface of biochars, forming a larger adsorption capacity. Micropore volume had a very significant positive correlation with total pore volume and specific surface area, indicating that micropores played a key role in promoting the formation of large surface area and large pore volume. The average pore size was negatively correlated with $q_{\mathrm{m}}, n$ and $k_{\mathrm{f}}$. The increase of the average pore size means the formation of pore with larger size, which would reduce the number of micropores and mesopores, leading to the decrease of specific surface area. It was also illustrated by the negative correlation between average pore size and $S_{\mathrm{BET}}$. The biochar activated by potassium carbonate had a marked increase in surface aromaticity, hydrophobicity and non-polarity, as well as richer pore structure and larger specific surface area, so the adsorption capacity for naphthalene was greater.

Except for alkyl groups, the major oxygen-containing functional groups of KBC450 and KBC600 did not disappear as the pyrolysis temperature increasing (Fig. 5). This was one of the

Table 4 Correlation coefficient of the adsorption constants and the structural characteristics of biochars ${ }^{a}$

\begin{tabular}{|c|c|c|c|c|c|c|c|c|c|c|}
\hline & $\mathrm{H} / \mathrm{C}$ & $\mathrm{O} / \mathrm{C}$ & $(\mathrm{O}+\mathrm{N}) / \mathrm{C}$ & $S_{\mathrm{BET}}$ & $V_{\mathrm{T}}$ & $V_{\text {mic }}$ & $V_{\text {mes }}$ & $\begin{array}{l}\text { Average pore } \\
\text { width }\end{array}$ & $n$ & $k_{\mathrm{f}}$ \\
\hline $\mathrm{O} / \mathrm{C}$ & 0.843 & & & & & & & & & \\
\hline$S_{\mathrm{BET}}$ & $-0.963^{*}$ & -0.839 & -0.821 & & & & & & & \\
\hline$V_{\mathrm{T}}$ & $-0.953^{*}$ & -0.846 & -0.832 & $0.999 * *$ & & & & & & \\
\hline$V_{\text {mic }}$ & $-0.966^{*}$ & -0.852 & -0.832 & $1.000^{* *}$ & $0.999 * *$ & & & & & \\
\hline$n$ & $-0.957^{*}$ & -0.781 & -0.759 & $0.995^{* *}$ & $0.992 * *$ & $0.992 * *$ & 0.893 & -0.946 & & \\
\hline$k_{\mathrm{f}}$ & $-0.964 *$ & $-0.954^{*}$ & -0.915 & 0.927 & 0.924 & 0.936 & 0.838 & -0.722 & 0.895 & \\
\hline$q_{\mathrm{m}}$ & -0.907 & $-0.990 *$ & $-0.963 *$ & 0.880 & 0.881 & 0.892 & 0.844 & -0.616 & 0.832 & $0.986^{*}$ \\
\hline
\end{tabular}

$a *$ indicates significant correlation at $p<0.05$ level. **indicates significant correlation at $p<0.01$ level. 


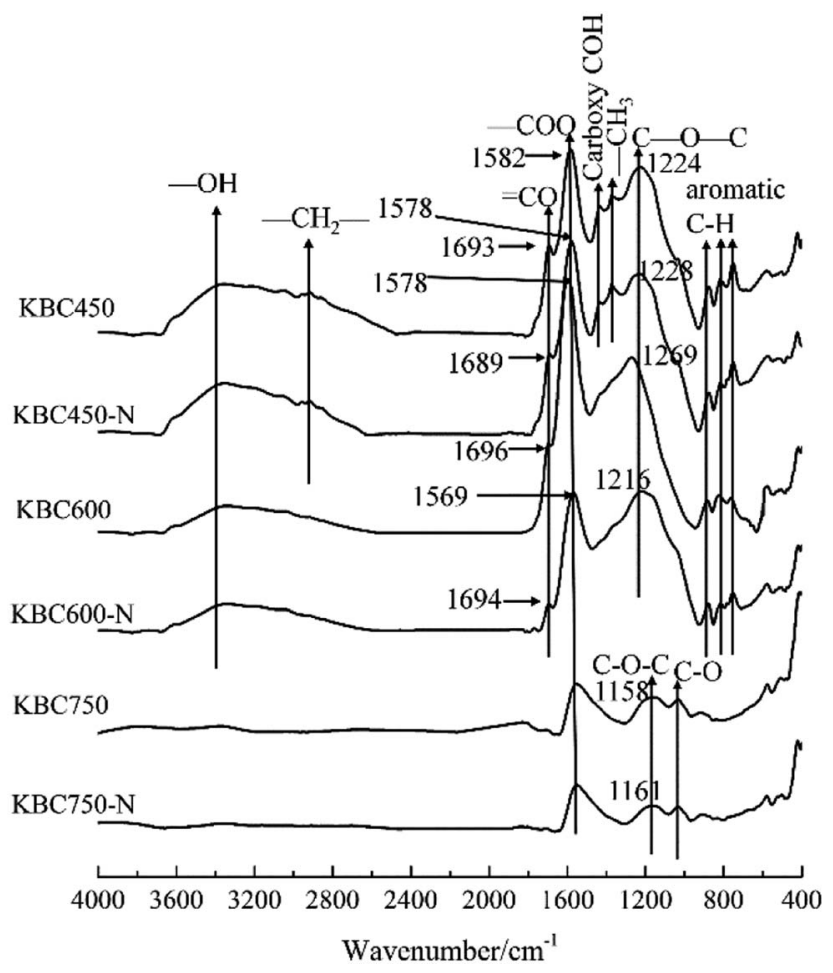

Fig. 5 FTIR of KBC before and after adsorbed naphthalene. $\mathrm{N}$ indicates that naphthalene has been adsorbed, and the values indicated by the arrows represent the change of wavenumber corresponding to the absorption peak before and after the adsorption of naphthalene.

reasons why there was no difference between $\mathrm{O} / \mathrm{C}$ and $(\mathrm{O}+\mathrm{N}) / \mathrm{C}$ for KBC450 and KBC600. As the pyrolysis temperature increases, the oxygen-containing functional groups on the $\mathrm{KBC}$ surface gradually decreased. When the temperature was raised to $750{ }^{\circ} \mathrm{C}$, the absorption peak of hydroxyl group ${ }^{33}$ and carboxyl group $\mathrm{C}=\mathrm{O}^{34}$ disappeared, and the absorption peak of carboxyl group and ether bond ${ }^{\mathbf{1 6}}$ was strongly impaired. The disappearance of the aromatic $\mathrm{C}-\mathrm{H}$ vibration ${ }^{35}$ indicated that the carbon atoms were arranged more closely. High pyrolysis temperature coursed the graphitization of KBC. These changes were conducive to the formation of non-polar hydrophobic surface. Before and after the adsorption of naphthalene, there was no obvious change in the infrared spectrum of biochar surface except for the displacement of absorption peak wavenumber of oxygen functional group (Fig. 5). It suggested that naphthalene adsorbed on the surface of KBC may not form a new chemical bond, but it was fixed on the KBC surface by conjugation or van der Waals force. ${ }^{36,37}$ The aromatic structure of naphthalene can serve as an electron donor and undergo $\pi-\pi$ electron-donoracceptor $(\pi-\pi$ EDA $)$ interaction with the electron-deficient aromatic structure on the surface of $\mathrm{KBC}^{38}$ For example, the absorption peak at $1158 \mathrm{~cm}^{-1}$ was due to the $\mathrm{C}-\mathrm{O}-\mathrm{C}$ stretching vibration associated with the aromatic ring/olefin. ${ }^{39}$ After adsorption of naphthalene by KBC, the absorption peak shifted to high frequency, indicating the interaction between naphthalene and the oxygen-containing functional groups of biochar and the existence of $\pi-\pi$ EDA. ${ }^{40}$

\section{Conclusion}

After being activated by potassium carbonate, the surface properties of biochar changed with the increase of temperature. The aromaticity of KBC increased with the increase of temperature, and the non-polarity and hydrophobicity were the highest at $750{ }^{\circ} \mathrm{C}$. The porosity on the surface of biochar increased greatly with the activation of potassium carbonate, and the wall of the pores would be ruptured if the activation temperature exceeded $600{ }^{\circ} \mathrm{C}$. At the mesoscopic level, the pore distribution was dense and the microporous-mesoporous composite structure existed inside. This composite structure was beneficial to the diffusion of pollutant molecules. The adsorption isotherms of naphthalene on biochar could be fitted well by Langmuir model and Freundlich model. The maximum adsorption capacity had a good correlation with the hydrophobicity and non-polarity of biochar. $\pi-\pi$ EDA was the main adsorption mechanism. The specific surface area and surface chemical property played important role in the adsorption process, meanwhile good pore structure was an indispensable key element to increase the adsorption capacity. Good pore structure had both macroporous, mesoporous and microporous, and was reasonably distributed on the internal and external surfaces of biochar. Non-polar and hydrophobic biochar surfaces are more suitable for adsorbing naphthalene.

\section{Conflicts of interest}

There are no conflicts to declare.

\section{Acknowledgements}

This research was supported by the National Natural Science Foundation of China (No. 41271331, 41571317). Many thanks to associate professor Feng Huang from College of Resources and Environment, China Agricultural University for his support for the revision of this paper.

\section{References}

1 M. Safaei Khorram, Q. Zhang, D. Lin, Y. Zheng, H. Fang and Y. Yu, J. Environ. Sci., 2016, 44, 269-279.

2 N. Zhao, X. Yang, J. Zhang, L. Zhu and Y. Lv, Materials (Basel), 2017, 10, 1119.

3 M. Ahmad, A. U. Rajapaksha, J. E. Lim, M. Zhang, N. Bolan, D. Mohan, M. Vithanage, S. S. Lee and Y. S. Ok, Chemosphere, 2014, 99, 19-33.

4 M. A. Yahya, Z. Al-Qodah and C. W. Z. Ngah, Renewable Sustainable Energy Rev., 2015, 46, 218-235.

5 B. Stöhr and H. P. Boehm, Carbon, 1991, 29, 707-720.

6 S. Wang and G. Q. Lu, Carbon, 1998, 36, 283-292.

7 R. L. Tseng, J. Colloid Interface Sci., 2006, 303, 494-502.

8 A. K. Dalai and R. Azargohar, ACS Symp. Ser., 2007, 954, 463476.

9 D. Kibami, C. Pongener, K. S. Rao and D. Sinha, Der Chemica Sinica, 2014, 5(4), 46-55. 
10 U. Iriarte-Velasco, I. Sierra, L. Zudaire and J. L. Ayastuy, Food Bioprod. Process., 2016, 98, 341-353.

11 S. Li, J. Lu, T. Zhang, Y. Cao and J. Li, Water Sci. Technol., 2017, 75, 482-489.

12 Y. Y. Wang and Y. Z. Lu, Spectrosc. Spectral Anal., 2016, 36, 3292-3296.

13 M. B. Ahmed, J. L. Zhou, H. H. Ngo, W. Guo and M. Chen, Bioresour. Technol., 2016, 214, 836-851.

14 X. Jing, Y. Wang, W. Liu, Y. Wang and H. Jiang, Chem. Eng. J., 2014, 248, 168-174.

15 M. B. Ahmed, J. L. Zhou, H. H. Ngo and W. Guo, Sci. Total Environ., 2015, 532, 112-126.

16 R. Li, Z. Wang, J. Guo, Y. Li, H. Zhang, J. Zhu and X. Xie, Water Sci. Technol., 2018, 77, 1127-1136.

17 D. A. D. Genuino, M. D. G. De Luna and S. C. Capareda, Waste Manag., 2018, 72, 255-264.

18 S. Kloss, F. Zehetner, A. Dellantonio, R. Hamid, F. Ottner, V. Liedtke, M. Schwanninger, M. H. Gerzabek and G. Soja, J. Environ. Qual., 2012, 41, 990-1000.

19 D. Angin, E. Altintig and T. E. Kose, Bioresour. Technol., 2013, 148, 542-549.

20 P. Liao, S. Yuan, W. Zhang, M. Tong and K. Wang, J. Colloid Interface Sci., 2012, 382, 74-81.

21 S. L. Zhang, L. C. Tao, Y. L. Zhang, Z. K. Wang, G. J. Gou, M. Jiang, C. P. Huang and Z. W. Zhou, Powder Technol., 2016, 295, 152-160.

22 R. J. Evans and T. A. Milne, PLoS One, 1987, 6, 123-137.

23 M. Nishimura, S. Iwasaki and M. Horio, J. Taiwan Inst. Chem. Eng., 2009, 40, 630-637.

24 D. W. Mckee, Carbon, 1982, 20, 59-66.

25 K. S. W. Sing, Pure Appl. Chem., 1985, 57, 603-619.
26 Y. Ngernyen, C. Tangsathitkulchai and M. Tangsathitkulchai, Korean J. Chem. Eng., 2006, 23, 1046-1054.

27 G. Tan, W. Sun, Y. Xu, H. Wang and N. Xu, Bioresour. Technol., 2016, 211, 727-735.

28 D. K. Mahmoud, M. A. M. Salleh, W. A. W. A. Karim, A. Idris and Z. Z. Abidin, Chem. Eng. J., 2012, 181-182, 449-457.

29 Z. Wang, J. Wu, T. He and J. Wu, Bioresour. Technol., 2014, 167, 551-554.

30 A. M. Dehkhoda, E. Gyenge and N. Ellis, Biomass Bioenergy, 2016, 87, 107-121.

31 G. Jiang, X. Quan, J. Liu, L. Zhu and L. Guo, Environmental Nanoscience and Technology, Science Press, Beijing, 2015.

32 H.-H. Cho, B. A. Smith, J. D. Wnuk, D. H. Fairbrother and W. P. Ball, Environ. Sci. Technol., 2008, 42, 2899-2905.

33 W. Wu, J. Li, N. K. Niazi, K. Muller, Y. Chu, L. Zhang, G. Yuan, K. Lu, Z. Song and H. Wang, Environ. Sci. Pollut. Res. Int., 2016, 23, 22890-22896.

34 X. Song, K. Li, P. Ning, C. Wang, X. Sun, L. Tang, H. Ruan and S. Han, Appl. Surf. Sci., 2017, 425, 130-140.

35 M. Uchimiya, L. H. Wartelle, K. T. Klasson, C. A. Fortier and I. M. Lima, J. Agric. Food Chem., 2011, 59, 2501-2510.

36 M. Vithanage, S. S. Mayakaduwa, I. Herath, Y. S. Ok and D. Mohan, Chemosphere, 2016, 150, 781-789.

37 C. Jiang, H. Cai, L. Chen, L. Chen and T. Cai, Environ. Sci. Pollut. Res. Int., 2017, 24, 3861-3871.

38 K. Yang, W. Wu, Q. Jing, W. Jiang and B. Xing, Environ. Sci. Technol., 2010, 44, 3021-3027.

39 D. Feng, Y. Zhao, Y. Zhang, J. Gao and S. Sun, Fuel Process. Technol., 2017, 165, 72-79.

40 F. Lian, B. Sun, X. Chen, L. Zhu, Z. Liu and B. Xing, Environ. Pollut., 2015, 204, 306-312. 